\title{
CONSTRUCTING THE CORPORATE INSTAGRAM DISCOURSE - A CRITICAL VISUAL DISCOURSE APPROACH
}

\author{
Søren Vigild Poulsen \\ University of Southern Denmark, Denmark \\ vigild@sdu.dk
}

\begin{abstract}
Since October 2010, the Instagram app has provided its users with means of visual communication that previously were reserved for professional photographers. Simultaneously, the Instagram Corporation's official blog has offered suggestions on how the features of the app could be applied. In this manner, the corporation has established a norm of Instagram use. Norms of technology use, i.e., socially learned ways of behaving and communicating with technology, are well-researched in technology and science studies, but thus far these studies have only included social media, e.g., Instagram, to a minor degree. Furthermore, it remains largely unexplored how these social rules are represented multimodally in discourses about social media technology. Through a critical multimodal discourse analysis, this paper describes how the aforementioned corporate regulative norms on the usage of Instagram were established on the corporate blog
\end{abstract}

Digital Age in Semiotics \& Communication, Vol. I, No. 1, Spring 2018, Pp. 95-112 
from 2010 to 2014. The findings show that the discourse on the blog adjusts its focus. Initially, it dealt with correctional tools for the app, but it then progressed into presenting tools for experimental visual expression. At the same time, the blog confines the experimental uses of the application and, thereby, the possible perception of what entertaining imagery is. This way, the study demonstrates how the Instagram Corporation seeks to regulate the use of the app.

Keywords: social media, critical multimodal analysis, Instagram, normative discourse, semiotic technology.

\section{Introduction}

Since October 2010, the Instagram corporation ${ }^{1}$ has provided its users with a means of visual communication previously reserved for professional photographers, along with a social network site for users to share photos and videos. At the same time, the Instagram corporation's official blog (blog.instagram.com) has offered suggestions, both visually and in writing, on how the app's tools could be applied. The blog also includes and promotes images from users that have made creative use of relevant tools, e.g. for a social event or particular use of a new filter. Thus the organization uses their blog and social networking site in specific ways as corporate communication to create a specific framework of knowledge or discourse.

Corporate use of social media remains an emergent field in discourse studies (Darics 2015; Danielewicz-Betz 2016). More specifically, further investigation is required of the ways in which businesses and organizations construct discourses through social media, and the applications of these discourses for the social practices of professional communication.

(Multimodal) discourse studies have paid attention to social media (Page et al. 2014; Adami \& Carey 2016), but most studies center on Twitter and Facebook (e.g., Eisenlauer 2013) rather than Instagram. And, while discourse studies of Instagram have taken an interest in user groups, for instance, mommy bloggers (Zappavigna 2016, Zhao \& Zappavigna 2016), politicians (Avedissian 2016), and location-based groups (Manovich 2016), no studies seem to have looked at the Instagram corporation and their communicative practices. This study seeks to provide more knowledge in this intersection of social media, visual discourse, and corporate communication.

\footnotetext{
${ }^{1}$ Instagram was bought by Facebook in April 2012, but I shall refer to Instagram as an independent company.
} 
Based on an ongoing study of the discourse on Instagram's corporate blog from 2010 to 2016, this article provides a critical visual discourse analysis ${ }^{2}$. The article seeks to demonstrate that the blog generates a special use of images, and from this basis, the study attempts to elucidate which visual resources the Instagram corporation uses to realize its discourse. By specifically centering on blog posts that encompass the use of tools in the app's user interface, this article shall study the construction of the corporate blog's discourse in addition to the discourse's corporate communicative context. As part of the research, this article investigates how the Instagram corporation frames uses of the app and notions of visual creativity through visual discourse. In doing so, the study demonstrates to what extent the Instagram corporation seeks to regulate the use of the app, and impose a norm that constrains other notions of visual creativity.

The article is structured in six sections: Following this introduction, I introduce the theoretical framework and methodology for the study in sections two and three. Sections four and five present the findings of the critical visual discourse analysis, with my concluding remarks in section six.

\section{Theoretical framework}

To investigate the ways in which Instagram constructs a normative discourse, this study employs critical visual discourse analysis both as theoretical framework and methodology (Kress \& van Leeuwen 2001, 2006; Martin \& Rose 2003; van Leeuwen 2005, 2008). In this framework, discourses are not understood as texts or speech, but "as socially constructed ways of knowing some aspect of reality" (van Leeuwen 2016: 138) that people use when they think, communicate and act. Thus, discourses are the frames people draw on in various sense-making social practices. In this case, I explore how the Instagram corporation makes meaning about the application and, thus, prompts its users to understand and engage with the Instagram app. Discourse is based on practices that are "context-specific frameworks of making sense of things" (ibid.) within specific social groups. This way, the study reconnects discourse to social practice, i.e., socially regulated ways of doing, "from which it derives (context-specific) meaning" in order "to analyze the processes of transformation, or recontextualization (Bernstein 1981, 1986), that occur as practices are turned into discourses" (van Leeuwen 2016, 139).

\footnotetext{
${ }^{2}$ The analysis of the discourse realized in writing is explored in forthcoming work (Poulsen, in preparation); in this article, I will attempt to reconstruct the discourse based on the images.
} 
It is a fundamental assumption that the discourse not only recontextualizes the social practice of making pictures, but also transforms practice in the process of representation. Van Leeuwen $(2005,2008$ a) suggests that transformations in discourse may include substitutions, deletions, rearrangements, and additions of elements to (representation of) social practice. Additions are subdivided into three important kinds: purposes, legitimations, and evaluations. Van Leeuwen has, to a great extent, shown how these transformations are expressed in texts. In this article I will use his analytical concepts slightly differently, to describe Instagram's use of their blog's constructed discourse. With inspiration from the concept of additions, I focus not on how such transformations occur in the visual discourse itself, but on how images, and the discourse they express, are used communicatively on the corporate blog. As shown by Wu (2016), a corporate blog combines different text types, which serve different communicative purposes and functional goals. Thus, a close inspection of discourse use indicates the social actors' interests and rhetorical strategies (Kress 2010) that form part of the communicative context of Instagram's corporate blogging.

Given that people use all available means to represent aspects of their reality, discourse analysis is concerned with the multimodal realization of discourse. As there is no generally accepted definition of mode (see Bateman 2008; Kress 2010 for discussions of mode), I provide a working definition for pragmatic reasons: a mode is a semiotic system that affords people with a bundle of resources for making meaning in social contexts. Thus, a discourse analysis must not only focus on writing but also on images, and on the interaction between these two primary modes used on the Instagram blog. In this article, which is part of a larger study, I primarily focus on images as a semiotic mode.

Since discourses do not exist independently of their expression (van Leeuwen 2016), by looking at the visual means employed by Instagram, one can characterize the realization of discourse in texts. On this basis, I can reconstruct which visual semiotic resources are employed to create (a) which parts of the discourse, (b) how viewers are established in relation to visual representations, as well as (c) how these two dimensions of meaning are organized. These three dimensions of meaning are termed the ideational, the interpersonal, and the textual metafunction, respectively (Halliday 1978). 
In other words, to describe the kind of discourse constructed, the analysis takes, as its point of departure, a description of how discourse is made by means of visual 'grammar' (Kress \& van Leeuwen 2006). By grammar I refer to an analytical description of how meaning making and visual resources are socially regulated.

Also, this study is critical. By critical I mean an analysis that investigates and makes explicit assumptions, justifications, arguments and rationale for discourse construction. In this way, the study is part of a critical tradition (Fairclough 1993; Wodak \& Meyer 2015). The study seeks to contribute with knowledge that which otherwise remains unspoken, taken for granted, or thought of as common-sense by Instagram users. Following Machin \& Mayr (2012), I assume that analytical description is a form of critique, and thus that analysis provides knowledge for people to question and debate. As a discourse analyst, my findings are not seen from a privileged position, and they are themselves informed by an academic discourse I must be aware of when identifying potential bias. 11

\section{Methodology}

In this analysis, I seek to answer two questions: firstly, what meaning is constructed visually on the Instagram blog, and second, what is this meaning used for the corporate blog? For the first part of this article, I will analyze the visual discourse and its realization in terms of different kinds of metafunctions. For the second part, I focus on the function(s) of visual meaning on the blog. I will divide the description of discourse into a grammatical level and a meaning level, cf. the division of strata in Halliday's $(1978,1985)$ Systemic Functional Linguistics (SFL). The grammatical level concerns the way discourse is construed, while the level of meaning concerns the kind of discourse constructed.

This study introduces selected methods for the analysis of visual discourse on which Instagram draws when it blogs about tools for making, editing and sharing pictures and videos in the app's user interface. The specific analytical terms listed in Table 1 will be explained. The terms are selected for existing work of visual social semiotics (Kress \& van Leeuwen 2006) and critical discourse analysis (van Leeuwen 2006, 2008). The listed terms represent only part of an exhaustive analysis; I adopt Machin \& Mayr's (2013) tool kit approach where analytical concepts are included on the basis of their relevance to the analysis of visual data. 


\begin{tabular}{|l|l|l|l|}
\hline & $\begin{array}{l}\text { Ideational mean- } \\
\text { ing }\end{array}$ & $\begin{array}{l}\text { Interpersonal } \\
\text { meaning }\end{array}$ & $\begin{array}{l}\text { Interpersonal } \\
\text { meaning } \\
\text { Textual meaning }\end{array}$ \\
\hline $\begin{array}{l}\text { Grammatical } \\
\text { level }\end{array}$ & Transitivity & $\begin{array}{l}\text { Social distance } \\
\text { Social relation } \\
\text { Social interaction } \\
\text { Modality }\end{array}$ & $\begin{array}{l}\text { Information value } \\
\text { Salience }\end{array}$ \\
\hline Meaning level & $\begin{array}{l}\text { - entity } \\
\text { - activity Inclu- } \\
\text { sion/exclusion } \\
- \text { Involvement } \\
\text { - Categorization }\end{array}$ & Power & Periodicity \\
\hline
\end{tabular}

Table 1. Specific analytical terms

To study visual discourse, I look at texts (blog posts) about app tools in which Instagram uses images. Data for the analysis consists of 50 blog posts about tools, such as photo filters and editing and sharing functions, on the official corporate archive in 2010-2016 (blog.instagram.com/archive). These posts represent a small fraction of those that focus on specific topics as well as on individuals or groups of users. More specifically, I examine posts about the release of updated versions, the introduction of new tools, and posts on the use of photo filters and other editing and sharing tools. Images from these blog posts fall into two categories: user-generated images used with the users' permission to illustrate a feature or tool of the app; and images made by the Instagram corporation. Both types of images are used when Instagram shows visual examples of the tools presented.

By analyzing multiple texts that exist in the same context, I attempt to document the existence of and reconstruct the 'Instagram corporate discourse' based on my analysis and interpretation of blog posts. As Roderick (2016) puts it: "I strive to establish how such texts make tacit normative claims about the "nature" of technology and their uses through multiple semiotic modes such as language, images, typeface, and music" (p.5). This approach aims to document how 'Instagram discourse' is construed, changes, and shifts focus. I only analyze posts that explicitly mention tools in the app to focus on the ways the Instagram corporation itself chooses to construct a discourse. It could be argued that the analysis ought to include blog posts introducing how selected users apply in-app tools when making their photos. Such an analysis could arguably illuminate how In- 
stagram 'imposes' a normative discourse about certain types of app usage by only showing feature usage of selected users that coincides with these norms. While this is a valid point, I seek to map Instagram's own semiotic sense-making, and not that of users. Yet, a future analysis of blog posts about these selected users could, undoubtedly, bring more nuances to the findings of the current analysis.

\section{Visual discourse analysis of Instagram's corporate blog part 1: The discourse of images}

\subsection{Ideational meaning in blog images}

\subsubsection{The ideational grammatical level: Transitivity}

To analyze the ideation of images on Instagram's blog, I want to describe meaning on the grammatical level in terms of transitivity, the system that manifests ideation experiences as meaning. Analyzing transitivity in the blog images enables me to describe how representation of core elements of the discourse, the social actors, their actions, and their circumstances are expressed visually. The representation of these elements indicates the ways in which actors' actions are constructed, and also to what extent actors and things are assigned agency in the represented social practices.

Regarding ideation in images, visual representations can focus on activities or entities (Martin \& Rose 2003: 324). At the grammatical level, activities and entities are described in terms of processes that represent experience of reality as 'goings-on' - doing, happening, being, having, etc. (Halliday 1994: 106-8). Kress \& van Leeuwen (2006) define activities in images as 'narrative processes', that is to say visual vectors (e.g., a line or a body part) indicating an action, actors doing something associated with a specific social practice. Entities are termed 'conceptual processes', which is defined as visual processes that realize entities and structures. The images on the selected blog posts are primarily conceptual processes and only narrative processes to a limited degree. For instance, in the blog "Instagram Tips: Using Lux" (11.2.2012) shows a series of simple things (a church, a street, and car) (Figure 1).

In a few cases, participants perform a 'reactional process', this means, the process is realized by the person's gaze and indicates an internal process of reacting to something. One example of this process is found in the post "Instagram's Newest Filter: Willow" (Figure 2). Two participants, a cat in one image, and a woman playing the guitar in another image, perform the simple act of looking, and their line of sight realizes reaction processes.

Of the conceptual processes, we find mostly analytical processes, or processes that manifest whole-part-relations, identity and attributes of 
entities, and almost no classificatory processes. In other words, we find no processes that represent a class or group whose members share one or more properties. The only example seems to be images of a city (class) and similar-looking skyscrapers (members).
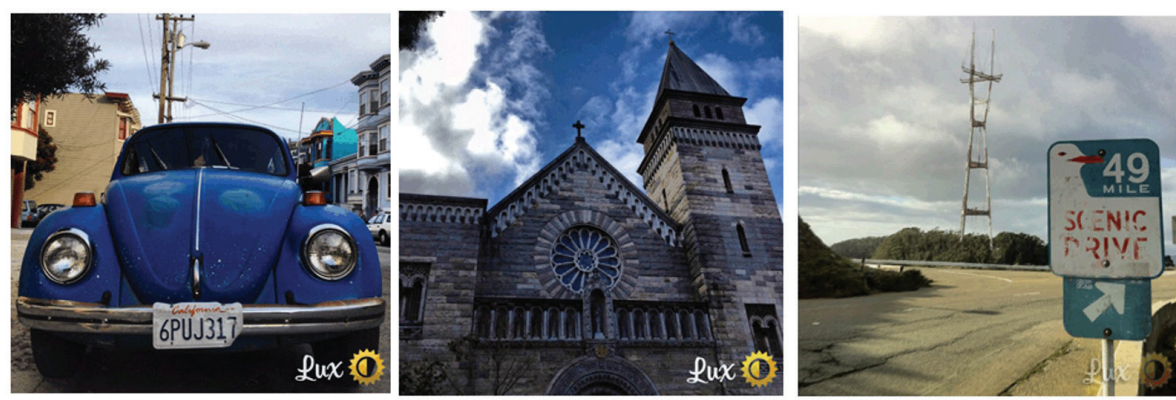

Figure 1. Examples of conceptual processes object on the blog post about using of the Lux tool. Source: http://blog.instagram.com/post/17436816889/ instagram-tips-using-lux (accessed 9.10.2017)
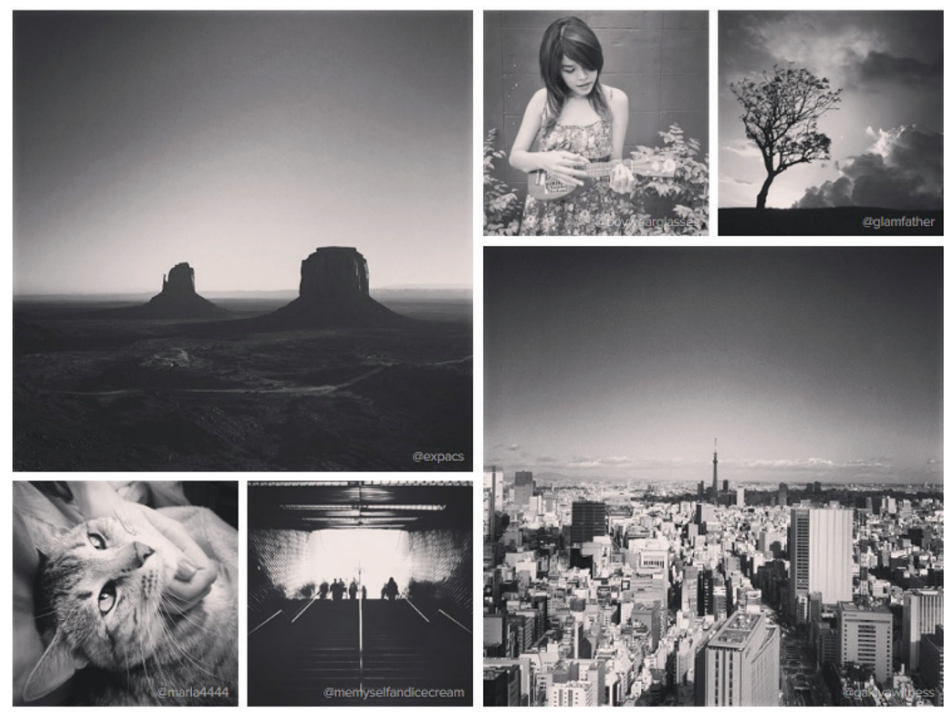

Figure 2. Examples of reactional process on the blog post about the Willow filter. Source: http://blog.instagram.com/post/37739409065/instagrams-newest-filter-willow-yesterdays (accessed 9.10.2017)

\subsubsection{The level of ideational meaning: Phenomenon focus, inclusion/ exclusion, and categorization}

In the previous section I analyzed the processes that make up the construal of grammatical-level image experience. I can now describe the 
meaning these processes realize. The analytical processes represent single motives, primarily animals, buildings, cityscapes and nature (e.g., the sky, a horizon, or trees). Blog posts that exemplify these entities are "\#hudson" (4.10.2011) and "Photo Tips: Straighten up!" (1.9.2011). Thus the images represent simple entities. It is important to notice that the pictures demonstrate the end result of a tool effect, that is, things users have taken pictures of; only in the cases where users take selfies, would one find representation of the social actions of mobile photography. But in the collected data, there are no selfies. Also, it is significant that in blog posts that launch new tools and/or reintroduce improved tools, people--both individuals and groups-are mostly absent. A reason for this might be that it is a legal matter. If so, it might be an attempt to draw attention away from the presented tool to the depicted motif. Nevertheless, Instagram's representation is focused on the pictures where people are excluded (van Leeuwen 2008). This exclusion can also be said to exemplify deletion as one way that the social practice of making mobile pictures is transformed (ibid.).

In the few cases, where people are depicted, they are represented individually, not in groups. And in these pictures of individuals, the persons are cast in generic categories, not specific (ibid.), for instance, a man, a woman or a baby, not particular identities. For instance, in blog post "Color and Fade" (7.4.2015), a woman is shown looking at something (realized by the reactional narrative process where the person's gaze indicates a vector) outside the picture frame. In a few cases, people directly at the camera are shown, as, for instance, on the blog post about face filters (21.9.2017).

On the basis of the visual represented ideation, one is able to identify an 'Instagram discourse': Its content consists of single, stand-alone things from an outside world. In this discursive world, people are almost not represented, while they, of course, exist and are present in reality.

\subsection{Interpersonal meaning in blog images}

4.2.1. The interpersonal grammatical level: Social distance, social relation, social interaction \& modality

If we now turn to how representations are constructed in relation to the viewer, images can be characterized in terms of their social distance. Put differently, social distance is the distance between the represented participant(s), that is people and/or things, and the viewer. Most images show the motives from a removed social distance from which you view the whole participant. In some cases, images are taken from a close personal distance. E.g., the blog post "How I Shoot Macro Nature Photos with @rickyhead" (5.8.2012) shows close up photos of insects, water drops and seeds (Figure 3). 


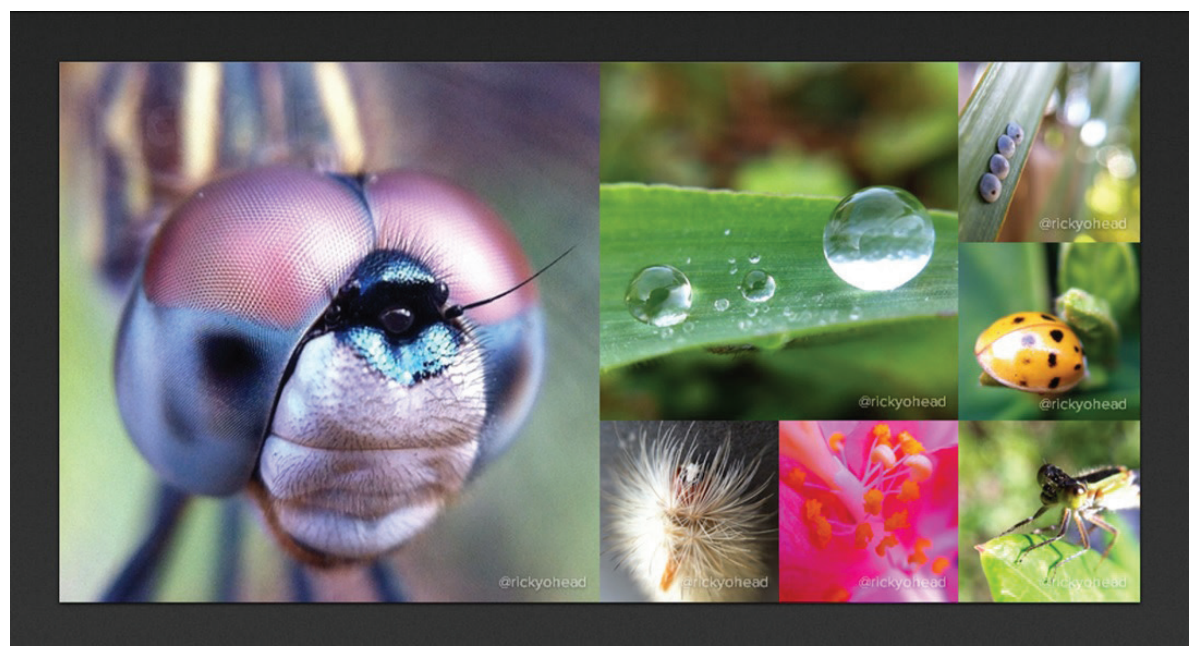

Figure 3. Examples of images with a close personal distance. Source: http:// blog.instagram.com/post/28766749799/macronaturephotos (accessed 9.10. 2017)

Since there are no people in most of the blog pictures, the social relation, i.e., the relation established between the image and viewer on the basis of image angle, can only be described on a vertical axle that determines whether an image is shot from a high, middle, or low angle. The horizontal axle that concerns the viewer's involvement in a depicted person's activity is irrelevant in the images. In the selected images, a simple description is that they are shot from a point of view that allows the viewer to see the motive from a neutral line of sight. Also, there is no social interaction, i.e., interaction between depicted persons and the viewer by way of a person's gaze.

As mentioned in the transitivity analysis, we only find a few photos depicting people and in those cases, the people mostly look to the side and thereby not at the viewer. In terms of social interaction, i.e., the interaction between the represented persons and the viewer, we would describe the interaction as an indirect address at the viewer.

The modality of the images, relating to the truthfulness or 'realness' of visual representation, is noteworthy. It is notable that all images appear impressive as a result of their colours. The modality of most images is high to medium. For instance, a blur or vibrance function creates a more naturalistic photo style. If we describe the images' modality markers (Kress \& van Leeuwen 2006), the images modify their representation of the truthfulness of the depicted participants by (for example) saturation, temperature, brightness, focus (depth of field), and detail. These markers relate to the 
resources that photo filters and other editing tools provide (for a description and discussion of resources of Instagram filters, see Poulsen 2017). What does this indicate? Each photo stands out and exemplifies that the discourse of Instagram makes photos beautiful, and this is also expressed in the blog's written text, for instance in the first blog post "Welcome to Instagram", 5.10.2010).

\subsubsection{The interpersonal meaning level: Power, engagement, appraisal}

In most images employed by Instagram, a vast social distance is used to create meaning that illustrates the visual effects a tool creates. The social distance that displays the motives in their entirety is combined with the neutral social relation, thus indicating an equitable power balance between the producer of the image and the viewer. The visual resources co-create an independent view. However, the indirect social interaction created in those images mostly without people also prompts a social encounter where the viewer either does interact or is invited to engage. The viewer is offered information and is positioned as a spectator rather than as someone who interacts. In this way, a discourse, that mainly centers on the viewing of 'things' in the world and only to a minor degree on viewing people who are absent, is constructed. From a critical perspective, this may seem like an odd choice since Instagram's mission is to enable its users to create engaging images and share them with their friends and relatives; in the blog post about introducing video from June 20, 2013, the corporation states: "Instagram has become a community where you can capture and share the world's moments simply and beautifully" (http://blog.instagram.com/ post/53448889009/video-on-instagram). The selected images on the blog challenge Instagram's concept that the app should enable users to make images that are not only beautiful but involve people and bring them together. The invitation to view, but not to engage, is further underscored by the mixed coding orientation, that is, "sets of abstract principles which inform the way in which texts are coded by specific social groups" (Kress \& van Leeuwen 2006: 165). The aptness to view the depicted subjects seems to be informed by a mix of two codes: one, a naturalistic coding orientation, where the judgment of the 'realness' of images is based on a naturalistic, common-sense representation of subjects. And second, a sensory coding orientation that supports the sensuous, pleasurable depiction of things. While the Instagram photos in the blog portray a naturalistic real world, the tools that the application provides enhance the colors, light, saturation etc. of these images. This photographic 'enhancement' creates more than 
real or super-naturalistic images, which may prompt the viewer to be impressed and even astonished by the visuals.

\subsection{Textual meaning in blog images}

\subsubsection{Grammatical level: Information value \& salience}

If we turn our attention to how the images are composed, the visual structures in the Instagram blog images can be described in terms of information value, meaning resources for organizing the visual information in the image frame, and salience, meaning resources for making participants significant in the image (Kress \& van Leeuwen 2006). Of the selected blog images, most are built up of a center-periphery structure in which the depicted participant is placed at the center of the image, while other participants are positioned in the visual margin. In some cases, the images are organized in a top-button structure. For instance, these information structures are found in images with a horizon that divides the images into two parts, one part above the horizon and the other part below it. In the post "Color and Fade" (7.4.2015), one finds an example of both information values: on two left image, a single, centered entity (a woman with sunglasses), (Figure 4)
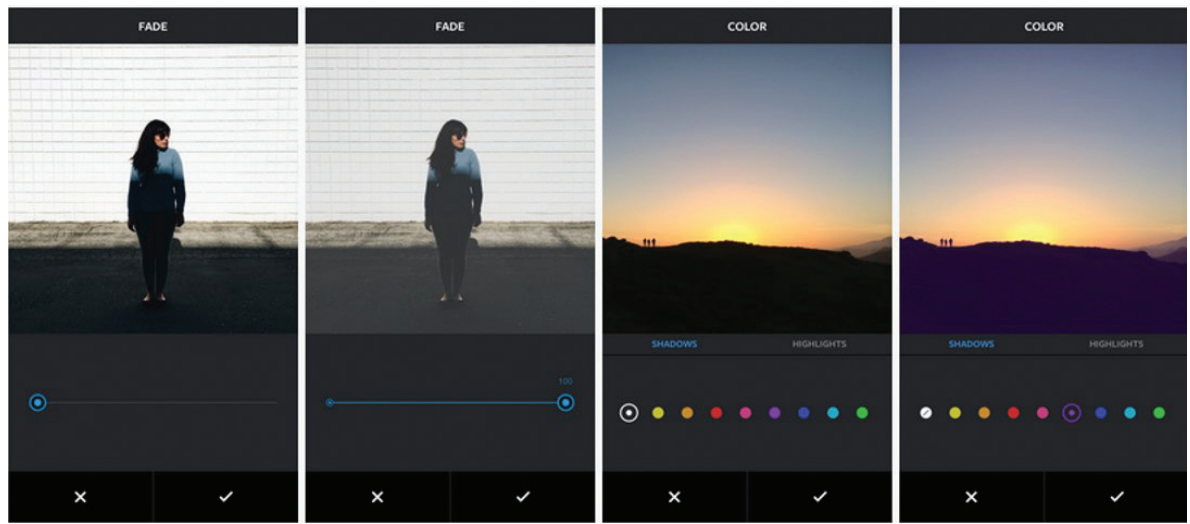

Figure 4 Examples of a center-margin structure (the two left images) and a top-button structure (the two right images). Source: http://blog.instagram. com/post/115772769267/150407-color-and-fade (accessed 9.10.2017)

Information organization resources co-create the visual meaning by making elements in the picture salient. As described by Kress \& van Leeuwen (2006), images employ various resources to make certain elements in the image stand out. In the blog images, these applied resources include 
focus, foreground-background, color, tonal contrast, and placement in the visual field.

\subsubsection{Textual meaning level: Periodicity}

Textual resources create a particular periodicity or flow of information. The center-periphery structure used in many of the blog images creates a textual meaning about the centered participant that is realized by the analytical process, cf. the ideational meaning level. Thus, the elements that inhabit the Instagram discourse, like buildings, nature, animals, are also placed center stage in the image. These centrally placed elements are further accentuated by salience markers such a tonal contrast and brighter color.

The top-bottom structure, on the other hand, is often used to bring out details of the photographed subject, e.g. leaves on threes or light and clouds in the sky. Again, this supports an aesthetics of the 'beauty' in things and the outside world that is depleted of people that the viewer simply looks at, but does not engage.

\section{Visual discourse analysis of Instagram's corporate blog part 2: The function of images}

\subsection{Discourse as recontextualization of the social practice of making} pictures

I will now turn to how the discursive meanings described in the above sections are used on the blog. To do so, I will describe the relation between discourse and social practices. The blog represents multimodally, in writing and images, the social practice of making mobile pictures. At the same time, blogging is a social practice within corporate communication that is enacted by the Instagram corporation on their official website. Drawing on multimodal social semiotics, the blog can be defined as a genre (van Leeuwen, 2005). As a genre, the blog recontextualizes the social practice(s) of mobile photography. It follows that the blog imports this practice from its own context into another context, that of the corporate blog, to represent it to the blog's audience and to use the represented practice of mobile photography to serve the purposes and interests of the Instagram corporation. Furthermore, the blog can draw on potential visual meanings made by users in their individual contexts.

Blogs are structured as a sequence of communicative actions, or speech acts (Martin 1992). In these sequences, images serve different communicative functions. Based on the selected data, I present three functions that I would argue can be identified: legitimation, purpose, and evaluation. This 
line of argumentation is inspired by van Leeuwen's (2008: 104-5) concept of additive discourse transformations. However, I use the terminology slightly differently to describe the communicative and rhetorical use of images on the blog, rather than how discourse transforms the represented practice by adding elements to the images themselves.

In the following, I will elaborate on these functions in the context of corporate blogging. I will, however, not go further into the analysis of the blog genre, or how the sequence of actions is organized and the kinds of actions it contains. This is the subject of another article that focuses on the written text of the Instagram blog. Also, therefore I only describe additive transformations of the represented social practice, leaving out other kinds of transformations.

\subsection{Communicative uses of the visual discourse}

The 'corporate Instagram discourse' changes and transforms the represented practice under the process of recontextualization. These transformations relate to the blog's communicative functions, specifically the use of images relating to legitimation, purpose and evaluation.

\subsubsection{Use of discourse I: Legitimization}

By incorporating user images in their corporate blog, Instagram borrows some of the potential meanings created by users through their mobile photo practices. Instagram thereby incorporates meaning made by users into its corporate blogging practice. In doing so, the images become a way to legitimize the in-app photo tools presented on the blog. As users have already applied a tool to make 'beautiful' images, they function as ambassadors for the applied tool and 'demonstrate' that the feature is approved by incorporating it in their own photographic practices. This technique, in which Instagram exploits user "approval," is frequently used on their blog. An example could be the post "\#Valencia" (13.10.2011), which shows images from users that have used this new filter, thus indirectly approving of it.

\subsubsection{Use of discourse II: Purpose}

Van Leeuwen $(2005,2008)$ argues that a common feature of discourse is to ascribe some purpose to the recontextualized practice. While in written discourse, this purpose may be expressed by adding a cause or an explanation in writing, e.g. "because ..." or "in order to ...", he does not offer examples on how such purposes can be represented visually. Yet I still find this kind of addition useful and relevant to the findings in this present analysis. 
Purpose is not represented in the images themselves, but in the use of images. I would argue that the use of the same image, as in the case of "Instagram 3.2. -Improved Camera with a New Filter" (10.12.2012), serves as an example of visual purpose. The same image is shown in two versions: one without Tilt-shift (a blur tool), the other in which the tool is used. In this way the images illustrate a before and after state and therefore function as a visual explanation of a tool's effect. Another example is found in the post describing what the user must do to (re-)create a tintype photo (posted on 9.6.2012). The images illustrate the purpose in terms of what a tool can do and how a beautiful image can be created. The purpose of the tool is, in this way, visually documented or exemplified.

\subsubsection{Use of discourse III: Evaluation}

When an image is presented on the blog, it realizes an evaluation made by the Instagram corporation as a social actor. The images exemplify what the corporation values as beautiful (alternatively, 'stunning' and 'amazing'). The series of blog post entitled "How I Shot" could serve as visual examples of evaluation. These images make up a style, and that style manifests an aesthetics (Kress 2010) affiliated with specific social groups (Adami 2014; Poulsen forthcoming). On these grounds, the images shown on the blog are subject to a (positive) evaluation of Instagram. They are heralded as examples of what Instagram judges to be beautiful images. While supporting visual creativity, the blog also enforces visual norms in its endorsement and selection of images.

\section{Conclusion}

This article reports on a study of the discourse on Instagram's corporate blog between 2010 and 2017. Given that the blog makes special use of images, the study describes the visual resources for realizing discourse. By focusing on blog posts about (the use of) tools in the app's user interface, the study explores discourse construction and its use in the context of business communication. The study uses critical visual discourse analysis to produce its findings. The corporate blog of Instagram includes user images to create a discourse of a (super-) naturalistic, sensually depicted outside world. Furthermore, the blog facilitates an aesthetics of 'things' that are singled out and presented as beautiful, stunning and amazing in their mere appearance. At the same time, people are almost absent in the selected images. Thus there are no social activities depicted and no social engagement depicted. The visual resources enact a neutral, indirect, and disengaged point of view, whereby the blog's viewer is positioned as a passive observer 
offered visual information, and who simply looks at the images presented. This study thus critiques the discourse for departing from Instagram's articulated company mission, a wish to enable sociality and the sharing of photos.

Instagram uses visually constructed discourse to attribute purpose, legitimation and evaluation to their social practice of corporate blogging. Firstly, the blog images illustrate what new and/or relaunched tools can do; in other words, they illustrate the tools' functional purpose. In this way the images become part of an explanation of tool usage. For instance, we are shown the same image in two different versions, before and after a tool's effect is applied. Furthermore, the images legitimize Instagram's new and/ or improved tools. The rational for this could be that the images 'document' the (beautiful) effects of the tools, while implying that the users who have already applied the tools in their mobile photo practices approve of them. It follows that the users and their images function as ambassadors for the app and the tools it provides. In other words, the tools have already been put to use by the Instagram community, and the Instagram corporation simply reports on the fact that the improved or designed tools enable users to make better images. Finally, the images facilitate an aesthetics of 'things'. When the images are embedded on the blog, Instagram endorses this aesthetics and indicates their approval of user-made images. 


\section{References}

Adami, Elisabetta. 2015. Aesthetics and identity in digital texts beyond writing: A social semiotic multimodal framework'. In Arlene Archer \& Esther Breuer (eds.), Multimodality in writing. The state of the art in theory, methodology, and pedagogy, 43-62. Leiden: Brill.

Adami, Elisabetta \& Caray Jewitt. 2016. Social media and the visual. Visual Communication [special issue], 15(3).

Avedissian, Karena. 2016. Clerics, weightlifters, and politicians: Ramzan Kadyrov's Instagram as an official project of Chechen memory and identity production. Caucasus Survey 1 (4,1). 20-43.

Bateman, John A. 2008. Multimodality and Genre: A Foundation for the Systematic Analysis of Multimodal Documents. Basingstoke, UK \& New York: Palgrave MacMillan.

Danielewicz-Betz, Anna. 2016. Communicating in digital age corporations. London: Palgrave Macmillan.

Darics, Erika. 2015. Digital Business Discourse. London: Palgrave Macmillan.

Eisenlauer, Volker (2013). A critical hypertext analysis of social mediaThe true colours of Facebook. London: Bloomsbury Academic.

Fairclough, Norman. 1993. Critical discourse analysis and the marketization of public discourse: the universities. Discourse \& Society 4(2). 133-168.

Halliday, Michael Alexander Kirkwood. 1978. Language as social semiotic. The social interpretation of language and meaning. London: Edward Arnold.

Halliday, Michael Alexander Kirkwood. 1985. An introduction to functional grammar. London: Arnold.

Instagram (2010-2016). Retrieved from https://www.blog.instagram. com (last accessed 9 September 2017).

Kress, Gunther. 2010. Multimodality - A social semiotic approach to contemporary communication. London/New York: Routledge.

Kress, Gunther \& Theo van Leeuwen. (2001). Multimodal discourse. The modes and media of contemporary communication. London: Arnold. 
Kress, Gunther \& Theo van Leeuwen. 2006. Reading images. 2.ed. London: Routledge.

Machin, David \& Andrea Mayr. 2012. How to do critical discourse analysis. A multimodal introduction. Los Angeles: Sage.

Manovich, Lev. 2016. Instagram and contemporary image. Retrieved from http://manovich.net/index.php/projects/instagram-and-contemporary-image (accesed 10.09. 2017.)

Martin, Jim R. \& David Rose. 2007. Working with discourse - Meaning beyond the clause. 2. ed. London/New York: Continuum.

Ruth Page, David Barton, Johann W. Unger and Michele Zappavigna. 2014. Researching language and social media: a student guide. Oxfordshire, England; New York, NY: Routledge.

Poulsen, Søren V. (forthcoming). Filtered aesthetics - a case study of Instagram's photo filters from a semiotic technology perspective. In: F. Forsgren \& E. S. Tønnessen (Eds.), Multimodality \& Aesthetics. Routledge.

Poulsen, Søren V. (in preparation).

Roderick, Ian. 2016. Critical discourse studies and technology - a multimodal approach to analysing technoculture. London: Bloomsbury.

Van Leeuwen, Theo (2015). Discourse as the recontuxtualization of social practice - a guide. In Ruth Wodak \& M. Meyer (eds.), Methods of critical discourse studies, 137-153. 3.ed. London: Sage.

Van Leeuwen, Theo. 2008. Discourse and practice: New tools for critical discourse analysis. Oxford: Oxford University Press.

Van Leeuwen, Theo. 2005. Introducing social semiotics. London: Routledge.

Wodak, Ruth E. \& Michael Meyer (eds.). 2015. Methods of critical discourse studies. 3rd ed. London: Sage.

$\mathrm{Wu}, \mathrm{Y}$. (2016). A corpus-based register analysis of corporate blogs. Unpublished PhD Thesis. Faculty of Law, Arts and Social Sciences, University of Leeds, UK.

Zappavigna, Michele. 2016. Social media photography: Construing subjectivity in Instagram Images. Visual Communication 15 (3). 271-292.

Zappavigna, Michele \& Sumin Zhao. 2017. Selfies in 'mommyblogging': An emerging visual genre. Discourse, Context \& Media. 